\title{
As traduções dos nomes próprios nas histórias em quadrinhos: um estudo de caso das tiras de Mafalda, de Quino
}

\author{
Translation of Proper Names in Comics: \\ Brazilian Translations of the Mafalda \\ Comic Strips, by Quino, as a Case in Point
}

\author{
Bárbara Zocal da Silva*
}

Resumo: Os nomes próprios têm como principal função identificar um referente. A tradução desses nomes envolve certas convenções literárias próprias de cada língua e existem muitos procedimentos possíveis dos quais os tradutores podem se valer para realizá-la. Dependerá do valor não ficcional - nomes que não acrescentam um significado por si só, embora possam conter um valor conativo ou fazer associações determinadas (GONZÁLEZ; GONZÁLEZ 1991) - e ficcional - quando o valor informativo do nome é tido como intencional, sendo considerado inclusive como descritivo (NORD 2003). A partir dessa discussão, o presente artigo descreve quais as práticas recorrentes na tradução dos nomes próprios em histórias em quadrinhos e identifica qual o referente priorizado nas três traduções brasileiras das tiras de Mafalda, de Quino.

Palavras-chave: Tradução de nomes próprios; tradução de histórias em quadrinhos; modalidades de tradução.

Abstract: Proper names have the primary function of identifying a referent. The translation of these names involves certain literary conventions particular to each

\footnotetext{
* Tradutora, pesquisadora e escritora. Mestra em Letras pela Faculdade de Filosofia, Letras e Ciências Humanas (FFLCH-USP). E-mail: barbara.zocal@gmail.com
} 
SILVA, B. Z. DA - Traduções dos nomes próprios nas histórias em quadrinhos: um estudo de caso das tiras de Mafalda, de Quino

language and there are many possible procedures on which translators can rely to carry these translations. It depends on the non-fiction value - names that do not add meaning by themselves, although they may contains a conative value or make certain associations (GONZÁLEZ; GONZÁLEZ 1991) - and the fictional value - when the informative value of the name is considered intentional, even as descriptive (NORD 2003). Starting from this discussion, this article describes what are the recurring practices in the translation of proper names in comics and identifies which referent was prioritized in three Brazilian translations of the Mafalda comic strips, by Quino.

Keywords: Proper names translation; comic strips translation; translation modalities.

\section{As tiras de Mafalda no mundo}

Há 50 anos, o quadrinista argentino Joaquín Salvador Lavado Tejón, mais conhecido por Quino, entretém leitores de todo o mundo com o humor crítico das tiras de Mafalda. As primeiras tiras da personagem foram publicadas na Primera Plana, em 1964, uma revista de atualidades políticas, econômicas e culturais. Segundo Quino (CIECHANOWER; Jolicoeur 1989: 53), esse contexto de publicação foi fundamental para moldar as características das personagens e das tiras, a fim de satisfazer os leitores da revista, que correspondiam à classe média argentina. Assim, logo nas primeiras tiras, o quadrinista aludiu a temas engajados socialmente, como os problemas econômicos e sociais dos países da América Latina, da China, da África e as relações de patriarcado.

Nos dois casos, tanto nas histórias sobre os países do terceiro mundo quanto naquelas que tratavam da condição feminina, eu queria usar os quadrinhos para voltar às situações, apesar da gravidade das questões levantadas. (CIECHANOWER; JOLICOEUR 1989: 53, tradução nossa). 
SILVA, B. Z. DA - Traduções dos nomes próprios nas histórias em quadrinhos: um estudo de caso das tiras de Mafalda, de Quino

Com o tempo, os temas abordados por Mafalda e seus amigos, direta ou indiretamente, foram ampliados para dar lugar a outros problemas da década de 1960: os golpes de estado na América Latina, os confrontos entre os Estados Unidos e a União Soviética, os Beatles, a missão Apollo XI, o fim da guerra do Vietnã, entre muitos outros acontecimentos.

As tiras tiveram boa repercussão mundial, foram traduzidas para muitos países e Quino acredita que Mafalda foi bem recebida na Europa devido às tiras se aproveitarem do boom latino-americano e da figura do Che Guevara. Em países europeus como a Espanha, Portugal - onde as primeiras traduções apareceram em 1970 - e a Grécia, houve afinidade dos leitores com a ambiência e os problemas retratados nas tiras que, em certa medida, eram semelhantes aos dos países latino-americanos. Afinal, Quino não duvidava que os problemas envolvendo as relações da família, da escola, dos amigos do bairro, da casa, da professora, dos vizinhos, dos pagamentos do carro ou do apartamento, do custo de vida e da inflação podiam ser compartilhados por muitos países (CIECHANOWER; JoliCOEUR 1989: 54). Curiosamente, a Inglaterra foi um dos países cujos leitores não compartilharam dessa empatia e as tiras não alcançaram grande popularidade.

No Brasil, as tiras da Mafalda são apreciadas desde a década de 1970 e tiveram suas traduções para o português brasileiro publicadas por três editoras distintas. As primeiras aparições da personagem aconteceram entre os anos 1972 e 1975 na Revista Patota, publicada pela Editora Artenova (RJ). Em 1982, Mafalda reapareceu numa coleção de cinco livretos lançados pela Editora Global (SP), traduzidos por Mouzar Benedito e editados por Henrique de Souza Filho, o Henfil. E desde 1991 até a atualidade, as publicações são realizadas pela Editora Martins Fontes (SP) e traduzidas, principalmente, por Monica Stahel.

Tendo em vista a ampla difusão e a grande popularidade das tiras de Mafalda, suas traduções brasileiras ofereceram um interessante material de pesquisa no que se refere à reflexão sobre características próprias da 
SILVA, B. Z. DA - Traduções dos nomes próprios nas histórias em quadrinhos: um estudo de caso das tiras de Mafalda, de Quino

tradução de histórias em quadrinhos (doravante HQs) e foram amplamente discutidos por Silva (2015). A pesquisa se propôs a observar 72 tiras de Mafalda em língua espanhola e a descrever o tratamento dado às três traduções brasileiras dessas tiras pelos diferentes tradutores, a partir de estudos de função (contextos) e de produto (textos). As tiras foram analisadas com base na taxonomia de procedimentos técnicos de tradução que Aubert (1998) adequou para examinar textos traduzidos e distâncias tradutórias entre pares linguísticos, as denominadas modalidades de tradução.

Este artigo discorre sobre as traduções dos topônimos e antropônimos, a partir de González; González (1991) e Nord (2003), conduzindo a discussão para o contexto das traduções dos nomes próprios nas histórias em quadrinhos, e apresenta os resultados obtidos das análises das tiras de Mafalda que compuseram o corpus da pesquisa desenvolvida por Silva (2015).

\section{A tradução dos nomes próprios}

A tradução de nomes próprios é marcada pelo mito da impossibilidade. Contudo, segundo Nord (2003: 183), se consideramos a tradução como um processo de transferência linguística e/ou cultural é evidente que os nomes próprios podem, de fato, ser traduzidos.

Há o consenso entre os pesquisadores de que os nomes próprios não acrescentam um significado por si só, embora possam conter grande valor conotativo ou fazer associações muito determinadas que serão distintas para cada indivíduo (GonzÁlez; GonzÁlez 1991: 50). No caso dos antropônimos, González; González (1991: 50) fazem a distinção entre a tradução dos nomes "motivados" e "não motivados". Os primeiros referem-se àqueles nomes

próprios cujo valor conotativo será essencial na narrativa, são nomes que foram atribuídos (pelo autor, por exemplo) com a intenção de representar ou 
SILVA, B. Z. DA - Traduções dos nomes próprios nas histórias em quadrinhos: um estudo de caso das tiras de Mafalda, de Quino

realçar alguma característica relacionada à personagem (como no caso do nome da personagem Cascão, da HQ Turma da Mônica ${ }^{1}$ ). Os antropônimos "não motivados" não possuem um significado intencionado, ainda que possa tê-lo etimologicamente; sua informação provém de nomes comuns e não se associa a nenhum conceito ou objeto (GonZález; GonZálEz 1991: 51).

Em pesquisas mais contemporâneas, inseridas no contexto dos estudos funcionalistas, no qual a tradução é um ato de comunicação intercultural que lida com sistemas culturais de partida e de chegada distintos, Nord (2003: 183) entende os nomes próprios como monorreferenciais, ou monossêmicos, diferentemente dos nomes genéricos; no entanto, não os vê de forma alguma como mono-funcionais, ainda que eles tenham como função principal identificar um referente individual. Além disso, a autora aponta ser frequente a afirmação de que os nomes próprios não têm significado descritivo (STRAWSON 1971: 23 apud NORD 2003: 183) e argumenta que, no mundo real, os nomes próprios podem não ser descritivos, mas eles são, evidentemente, informativos e denotam um tipo particular de referente. Se estivermos familiarizados com a cultura de partida em questão, os nomes próprios podem nos indicar se o referente é uma pessoa do sexo feminino ou masculino (por exemplo, Paula e Paulo), ou se trata de um nome de animal de estimação (por exemplo, Nina e Rex), ou de lugar etc. Na ficção, no entanto, esses indicadores podem ser assumidos como intencionais, quando autores usam nomes que descrevem explicitamente o referente em questão e podem ser considerados "nomes descritivos" (como no caso do nome do personagem Batman, o homem morcego).

Ao pensarmos em traduções de nomes próprios de textos ficcionais, existem certas convenções literárias, próprias de cada língua, que devem ser levadas em conta na tradução. Segundo Nord (2003: 184), uma dessas convenções é a dos nomes próprios como "marcadores culturais", ou seja, tais

\footnotetext{
${ }^{1}$ Ao longo do artigo, procuramos inserir exemplos com referentes do contexto brasileiro.
} 
SILVA, B. Z. DA - Traduções dos nomes próprios nas histórias em quadrinhos: um estudo de caso das tiras de Mafalda, de Quino

nomes podem indicar implicitamente a qual cultura o personagem pertence. $\mathrm{Na}$ literatura alemã, por exemplo, se há a presença de uma personagem de nome "Joséphine" em uma história com o enredo ambientado na Alemanha, ela será automaticamente assumida como francesa. Por outro lado, na literatura espanhola, os nomes próprios são geralmente adaptados à morfologia do espanhol. Se houver um médico chamado "don Federico" que apareça em um ambiente espanhol, não é possível identificar a nacionalidade dele a partir do nome; ele poderia ser de nacionalidade espanhola, alemã ou francesa, e se o autor quiser que o personagem seja reconhecido como alemão, por exemplo, ele terá que descrever explicitamente no contexto.

Ademais das convenções, os tradutores podem se valer de muitas técnicas na tradução de nomes próprios, como por exemplo a não-tradução (o nome do personagem Haddock, da HQ Tintin, se mantém em en., de., it., esp. $\left.{ }^{2}\right)$; a não-tradução que apresenta uma pronúncia diferente na língua-meta (en. Alice [ æl.is], fr. Alice [a'li:s], it. Alice [a'litche]); a transcrição ou a transliteração de alfabetos não latinos (rus. Шкловский, pt. Chklovski, es. Shklovski); a adaptação morfológica para a língua alvo (fr. Milou, es. Milú, it. Milù); a adaptação cultural (en. James, pt. Tiago); a substituição (pt. Cebolinha, en. Jimmy Five) e assim por diante.

Sendo assim, podemos perceber que não há regras herméticas que rejam a tradução de nomes próprios. Como dito anteriormente, qualquer que seja a função do nome próprio, ela é limitada a identificar um referente individual. Dessa forma, apesar das técnicas e convenções criadas e aceitas nas diversas línguas, o principal critério para a tradução de nomes próprios é fazer o trabalho de identificação da função desses nomes para o público alvo. É possível que os tradutores nem sempre usem as mesmas técnicas com todos

\footnotetext{
${ }^{2}$ As línguas estrangeiras tratadas no texto foram abreviadas, sendo assim, "en." corresponde a inglês, "it." a italiano, "es." a espanhol, "pt." a português brasileiro, "pt. eur." a português europeu, "fr." a francês, "de." ao alemão, "sven." ao sueco, "rus." ao russo e "ned." ao neerlandês.
} 
SILVA, B. Z. DA - Traduções dos nomes próprios nas histórias em quadrinhos: um estudo de caso das tiras de Mafalda, de Quino

os nomes próprios de um determinado texto e, em vista disso, é fundamental que prevaleça a coerência de manter uma padronização das traduções ao longo do texto.

\section{A tradução de nomes próprios nos quadrinhos}

Até a primeira metade do século $X X$, consagrou-se na cultura ocidental traduzir os nomes próprios ou, ao menos, adaptá-los à fonética particular de cada língua, principalmente quando a língua traduzida não era de raiz latina (GoNZÁLEZ; GonZÁLEZ 1991: 51). A tradução dos antropônimos nos quadrinhos não foge à regra.

No Brasil, segundo Reis (2012: 31), um dos principais procedimentos técnicos de tradução de nomes de personagens nessa época, que inclusive intitulavam as HQs, era o aportuguesamento. Os nomes traduzidos muitas vezes não faziam qualquer referência ao título na língua fonte, ou apenas destacavam alguma característica do personagem, como nos quadrinhos de Max und Moritz > Juca e Chico (Wilhelm Busch, 1865), L'il Abner > Ferdinando, Buscapé (Al Capp, 1934-1977), Beetle Bailey > Recruta Zero (Mort Walker, 1950), Dennis the Menace > Dennis, o Pimentinha (Hank Ketcham, 1951) e Katzenjammer Kids (The Captain and the Kids) > Os sobrinhos do Capitão (Rudolph Dirks, 1897).

Tal procedimento tradutório era uma maneira de colocar nomes que os brasileiros soubessem pronunciar e que de alguma forma chamassem a atenção dos compradores para consumir a literatura dos quadrinhos (REIS, 2012: 31). 
SILVA, B. Z. DA - Traduções dos nomes próprios nas histórias em quadrinhos: um estudo de caso das tiras de Mafalda, de Quino

Atualmente, o procedimento que se observa é a não-tradução de antropônimos, principalmente se tais nomes pertencem ao título da obra. Kaindl (2010: 38) observa que as traduções de títulos são consideradas critério de marketing e que, desde 1960, a tendência de manter os títulos na língua meta tem prevalecido, especialmente se eles incluem os nomes dos protagonistas, como no caso dos quadrinhos Turma da Mônica (en. Monica's Gang, es. Mónica y su pandilla), Les aventures de Tintin (en. The Adventures of Tintin, pt. As aventuras de Tintim) e Mafalda (en. Mafalda, pt. Mafalda, sven. Mafalda).

\section{A tradução dos nomes próprios nas tiras da Mafalda}

Aubert (1998: 103), por meio das modalidades de tradução, propõe uma forma de descrição do grau de diferenciação entre um texto-fonte e seus textos-meta em outras línguas, focalizando a descrição de produtos. Essa metodologia conduz a pesquisa de forma a gerar dados quantificáveis apropriados para tratamento estatístico. E para isso, o autor se concentrou em responder à indagação "quantos \% do texto original reaparecem no texto traduzido sob forma de determinada modalidade?" (AUBERT 1998: 103).

Silva (2015) considerou todas as modalidades propostas por Aubert (1998), com alguns acréscimos e modificações, que tiveram em vista atender às características que foram se mostrando relevantes para diferenciar os três subcorpora de traduções das tiras de Mafalda, e que derivaram basicamente de dois fatores: serem traduções no par linguístico português-espanhol e serem histórias em quadrinhos dotadas de linguagem verbal em sua narrativa, matéria com a qual o tradutor trabalha, mesmo que para isso se paute 
SILVA, B. Z. DA - Traduções dos nomes próprios nas histórias em quadrinhos: um estudo de caso das tiras de Mafalda, de Quino

também pelo contexto situacional das imagens em sua tradução. Sob mesmo questionamento de Aubert (1998), a autora identificou a ocorrência das principais modalidades presentes em cada uma das três traduções e os métodos de tradução ${ }^{3}$ escolhidos pelos tradutores, que apontavam ora para uma tradução fluente, ora para uma tradução que deixasse entrever o original em espanhol. Em seguida, traçou o perfil de cada tradutor relacionando-os aos contextos de produção dessas traduções.

Todas as palavras do corpus foram classificadas segundo os critérios de omissão, transcrição, empréstimo, decalque, tradução literal próxima, tradução literal distante, transposição facultativa, transposição obrigatória, implicitação, explicitação, modulação facultativa, modulação obrigatória, adaptação estilística, adaptação cultural, tradução intersemiótica, interferência lexical, interferência sintática, erro encoberto, erro evidente, correção e acréscimo.

$\mathrm{Na}$ análise e classificação das traduções dos nomes próprios levantadas para o presente artigo, encontramos com recorrência as seguintes modalidades: a) decalque - palavra ou expressão emprestada da língua-fonte (doravante LF) que foi submetida a adaptações gráficas e/ou morfológicas para conformar-se às convenções da língua-meta (doravante LM), ou que não se encontra registrada nos principais dicionários recentes da LF; b) empréstimo - segmento de texto do texto-fonte (doravante TF) reproduzido no texto-meta (doravante TM) com ou sem marcadores específicos de empréstimo (aspas, itálico ou negrito), como termos e expressões que tenham como referentes realidades antropológicas e/ou etnológicas específicas; c) transcrição - segmento de texto pertencente ao acervo de ambas as línguas envolvidas no TF e no TM (como algarismos, fórmulas algébricas e similares)

3 Hurtado Albir (2007: 249, tradução nossa) entende como “método de tradução" o “desenvolvimento de um processo de tradução determinado, regulado por certos princípios, em função do objetivo do tradutor; o método tem, consequentemente, um caráter supraindividual e consciente (ainda que, às vezes, possa ser inconsciente) e corresponde a uma opção global que percorre todo o texto".

TradTerm, São Paulo, v. 27, Setembro/2016, pp. 155-179

www.usp.br/tradterm

http://www.revistas.usp.br/tradterm/index 
SILVA, B. Z. DA - Traduções dos nomes próprios nas histórias em quadrinhos: um estudo de caso das tiras de Mafalda, de Quino

ou não pertencentes a nenhuma das duas línguas, mas, sim, a uma terceira língua (como frases e aforismos latinos); d) adaptação cultural - elemento pertencente a uma cultura que é substituído por um elemento próprio de outra em busca de maior adequação ao conhecimento de mundo de determinado público, ou a fim de direcionar a tradução para uma finalidade específica.

Outro critério que foi estabelecido para verificar se determinada opção de tradução era usual ou não na língua-meta foi comparar as frequências dos dados encontrados para uma ou outra palavra por meio do uso da ferramenta de busca Google, pois as buscas de palavras ou segmentos entre aspas informam também o número de ocorrências encontradas na internet.

Sendo assim, se para cada tradução de nome próprio é adotada uma técnica ou convenção específica, as classificações das traduções desses nomes também se diferem. Cada nome foi analisado particularmente, o que permitiu identificar a ocorrência das principais modalidades em cada tradução, entender e traçar o perfil de cada tradutor.

\section{A tradução dos antropônimos}

\subsection{Nomes dos personagens}

Os antropônimos dos personagens presentes no corpus não foram traduzidos, pois consistem em nomes "não motivados" (González; GonZÁlez 1991). Dentre todos os personagens das tiras de Mafalda, as únicas que apresentam nomes "motivados" são Libertad e Burocracia. A amiga de Mafalda, Libertad, tem um nome que descreve sua personalidade e sua condição de vida, pois é filha de pais socialistas e seu discurso está repleto de temas relacionados à revolução e à classe proletária. Já a tartaruga de 
SILVA, B. Z. DA - Traduções dos nomes próprios nas histórias em quadrinhos: um estudo de caso das tiras de Mafalda, de Quino

Mafalda e Guille recebeu o nome de Burocracia devido a sua lentidão. Porém, essas personagens não estão presentes nas tiras analisadas.

Os personagens que compuseram o corpus foram:

\subsubsection{Mafalda}

Segundo Quino (Quino 1988: 6), o primeiro propósito de criação das tirinhas da Mafalda foi servir como propaganda de produtos eletrodomésticos da empresa argentina Mansfield e uma das exigências da empresa na criação das tiras era que o nome do personagem principal iniciasse com a letra " $M$ ". Inspirado numa personagem bebê do romance Dar la cara, de David Viñas, Quino nomeou a protagonista das tiras de Mafalda.

O nome da personagem não foi traduzido em nenhuma das ocorrências presentes nas três traduções brasileiras, pois apesar de ser um nome de origem germânica, ele pertence tanto ao acervo da língua-fonte, o espanhol, como da língua-meta, o português. Devido a isso, o nome foi classificado, segundo as modalidades de tradução, como transcrição.

\subsubsection{Felipe}

O personagem Felipe, segundo o autor (QUINO 1988), foi criado em homenagem a seu amigo Jorge Timossi. Trata-se de um nome original do grego e que também pertence à onomástica portuguesa e espanhola. Nas traduções da Editora Artenova (doravante TA) e nas traduções da Editora Global (doravante TG), o nome não foi traduzido e foi mantido como no textofonte "Felipe"; porém, nas traduções da Editora Martins Fontes (doravante TMF) optou-se pela grafia "Filipe", a forma vernácula usada em Portugal.

No Brasil, convencionou-se usar a grafia de Felipe com a letra "e" como um arcaísmo de influência castelhana. Ao observarmos a frequência de uso das duas grafias na ferramenta de busca Google, constatamos que a grafia com a letra "e" é a mais usada em português em sites com extensão ".br", 
SILVA, B. Z. DA - Traduções dos nomes próprios nas histórias em quadrinhos: um estudo de caso das tiras de Mafalda, de Quino

obtivemos 9.320 .000 resultados versus 1.740 .000 resultados do nome grafado com "i".

Sendo assim, nas TA e nas TG a opção de tradução Felipe (esp.) > Felipe (port.) foi classificada como transcrição, enquanto nas TMF o nome foi classificado como decalque.

\subsubsection{Manolito}

Filho de um comerciante do bairro, o proprietário do armazém "Don Manolo", Manolito constitui uma caricatura do imigrante espanhol de origem galega. O nome do personagem é composto pelo hipocorístico "Manolo" do nome "Manuel", apelido que não existe na língua portuguesa, e pelo sufixo de diminutivo "-ito" (esp.), o sufixo mais neutro, frequente e menos marcado da língua espanhola. Apesar de também existir no português, o sufixo de diminutivo "-ito", ele não é nem o mais frequente, nem o menos marcado.

Diante do uso não frequente de "Manolo" em português e da formação do diminutivo própria do espanhol, classificamos Manolito, do ponto de vista morfológico, como empréstimo.

\subsubsection{Miguelito}

O nome do personagem Miguelito é formado a partir do nome "Miguel" e do sufixo de diminutivo masculino espanhol "-ito". Proveniente do hebraico, o nome foi usado em Portugal, primeiramente, no século II com a grafia Micael, e pertence à onomástica do português e do espanhol - encontramos 24.400.000 resultados da frequência de seu uso no Google em espanhol e 45.400 .000 resultados em português.

Como o nome Manolito, o nome Miguelito também foi classificado como empréstimo, devido ao sufixo diminutivo “-ito" (esp.) de um nome que caracteriza o universo da língua espanhola. 
SILVA, B. Z. DA - Traduções dos nomes próprios nas histórias em quadrinhos: um estudo de caso das tiras de Mafalda, de Quino

\subsubsection{Susanita}

Como o antropônimo do personagem Miguelito, o nome Susanita também é formado a partir do nome original do hebraico "Susana" e do sufixo de diminutivo feminino espanhol "-ita". Nas TG e nas TMF, os tradutores optaram pela não-tradução de "Susanita" e, nesse contexto, classificamos o nome como empréstimo.

Contudo, percebemos que as TA não seguiram uma padronização dos antropônimos durante toda a tradução, isto é, os tradutores alternaram ao longo das tiras entre a não-tradução do nome da personagem "Susanita" e sua tradução "Susaninha", como pode ser observado nos exemplos a seguir.

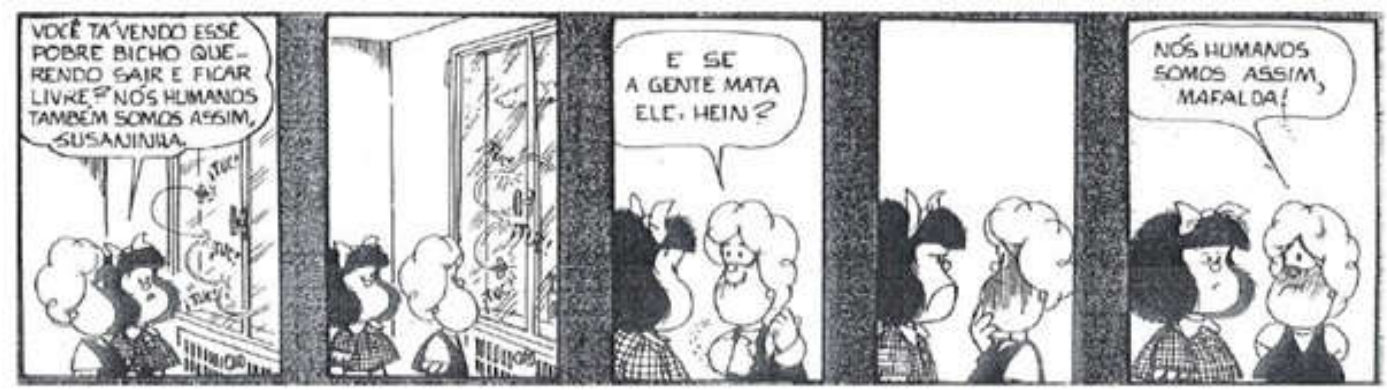

Figura 1: Extraído de PAтотA. Rio de Janeiro: Artenova, 1972-1974. Mensal. 27 volumes.

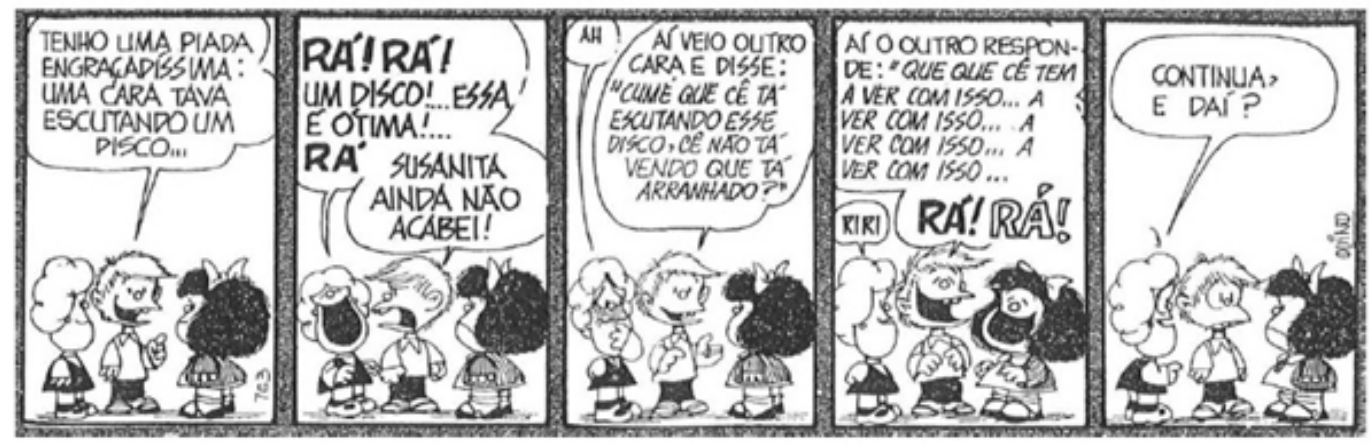

Figura 2: Extraído de PAтоTA. Rio de Janeiro: Artenova, 1972-1974. Mensal. 27 volumes.

No caso da tradução "Susaninha", o nome foi classificado como decalque, pois os tradutores reproduziram a morfologia do sufixo de 
SILVA, B. Z. DA - Traduções dos nomes próprios nas histórias em quadrinhos: um estudo de caso das tiras de Mafalda, de Quino

diminutivo feminino "-ita" da língua espanhola no sufixo de diminutivo feminino em português "-inha". Ainda que os dois sufixos sejam partículas que cumpram a mesma função morfológica e denotem carinho, e o sufixo "-ito(a)" seja usado em português - como, por exemplo, nos substantivos "cabrito" e "palito" -, quando agregados a antropônimos eles aludem a referentes distintos. Dessa forma, a tradução do nome provoca a perda do referencial hispânico por parte do leitor e descaracteriza o personagem enquanto oriundo de algum país da língua espanhola.

\subsection{Nomes biográficos}

As tiras da Mafalda abordam uma pluralidade de temas e estão repletas de referências a personalidades históricas. Nas tiras analisadas observamos a presença de antropônimos biográficos "não-motivados" (GonzálezZ; GonZález 1991) ou, segundo Nord (2003), "não descritivos", por serem nomes que pertencem ao mundo real. Apesar disso, esses nomes denotaram um referente particular que foi explorado nas tiras para se conseguir o efeito de humor. Esses nomes não foram traduzidos e atribuimo-lhes a modalidade transcrição para todas suas ocorrências nas três traduções.

\subsubsection{Fidel Castro}

Mafalda declaradamente não gosta de sopa e diz: "¿Por qué esse cretino de Fidel Castro no dice que la sopa es buena?". Nessa tira ${ }^{4}$, a referência que deve ser apreendida do nome de Fidel Castro, para que se consiga o efeito de humor desejado, é a de que ele, enquanto revolucionário comunista cubano, não deve ser seguido e tudo o que ele considera como certo é refutado pelos outros países, de base capitalista.

\footnotetext{
${ }^{4}$ As tiras do corpus podem ser lidas nos Anexos em Silva (2015).
} 
SILVA, B. Z. DA - Traduções dos nomes próprios nas histórias em quadrinhos: um estudo de caso das tiras de Mafalda, de Quino

\subsubsection{Moshe Dayan}

Manolito está posicionado em frente ao gol e diz a Susanita: “¡Dale, Susanita! ¡Jugá tranquila, que aqui tenés al Moshe Dayan de los guardavallas!”. Em um quadrinho, Manolito faz referência à reputação do otomano/israelense como um militar infalível, porém no quadrinho posterior leva uma bolada de Susanita no olho esquerdo, retomando o referente de Dayan e enfatizando, agora, o olho que ele perdeu em combate.

\subsubsection{William Shakespeare}

Felipe não queria fazer as tarefas da escola e divagou sobre personalidades que pudessem fazer essas atividades por ele. Em uma delas, Felipe recebe de seu servo a composição sobre a vaca que foi encomendada ao poeta e dramaturgo inglês William Shakespeare.

\subsubsection{Von Braun}

Miguelito comenta com Mafalda que sua professora fez os alunos copiarem repetidas vezes a soma “dos más dos es cuatro" e lastima que nunca se sentiu tão distante de Von Braun, fazendo, assim, referência à inteligência do engenheiro alemão que foi um dos principais responsáveis pelo desenvolvimento de foguetes na Alemanha Nazista e nos Estados Unidos.

\subsection{Nomes próprios fictícios}

Alguns nomes próprios fictícios foram mencionados nas tiras do corpus.

\subsubsection{Sioux e Morris Sucger}

Numa mesma tira, Sioux foi o nome usado para referir-se a um sentinela e Morris Sucger a um meteorologista. Trata-se de nomes fictícios, 
SILVA, B. Z. DA - Traduções dos nomes próprios nas histórias em quadrinhos: um estudo de caso das tiras de Mafalda, de Quino

"não motivados" e que não pertencem nem a LF (o espanhol) e nem a LM (o português), dessa forma eles foram classificados como transcrição.

\subsubsection{Schulz}

O nome próprio "não-motivado" Schulz, conforme apresentado na tira original, foi usado para referir-se ao personagem como alemão, provavelmente, por ser o nome estereótipo dessa cultura na Argentina. A tradução da Global manteve o nome não traduzido, que foi classificado, segundo as modalidades de tradução, como transcrição. No entanto, os outros tradutores perceberam essa particularidade e traduziram os nomes por outros que fossem mais familiares em português e cuja referência direta remetesse a um personagem alemão. A tradução da Artenova realizou uma adaptação cultural e substituiu Schulz por Fritz. Já a editora Martins Fontes realizou um decalque ao traduzir o nome para Schultz.

\subsubsection{Tía Clarita}

Há uma tira no corpus na qual Susanita conta para Mafalda sobre as xícaras de chá chinesas de sua tia Clarita. O nome é a junção do nome "Clara", proveniente do latim, e do sufixo de diminutivo feminino espanhol "-ita". Todas as traduções optaram pela não-tradução de "Clarita" que, nesse contexto, foi classificado como empréstimo.

\subsubsection{Pérez}

Numa das tiras, Mafalda busca pelo sobrenome Pérez na lista telefônica e se depara com um grande número de ocorrências, ele aparece 75 vezes nessa tirinha. $O$ humor se dá a partir da comparação feita pela personagem entre a grande quantidade de pessoas com o sobrenome Pérez em Buenos 
SILVA, B. Z. DA - Traduções dos nomes próprios nas histórias em quadrinhos: um estudo de caso das tiras de Mafalda, de Quino

Aires - cidade onde vivia seu criador, Quino, e considerada sua cidade natal e a grande população da China.
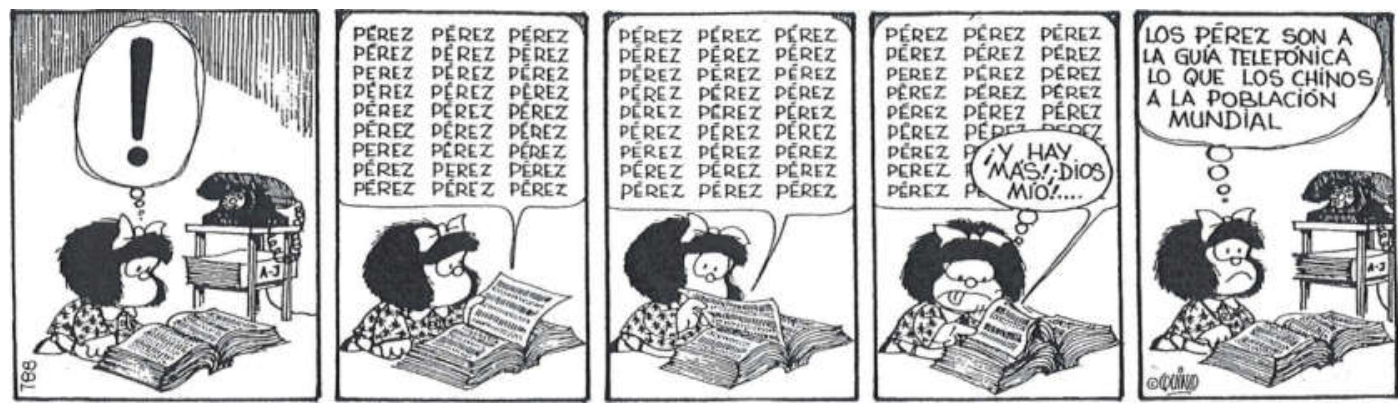

Figura 3: Extraído de QuINo. Toda Mafalda. 25. ed. Buenos Aires: Ediciones de la Flor, 2011.

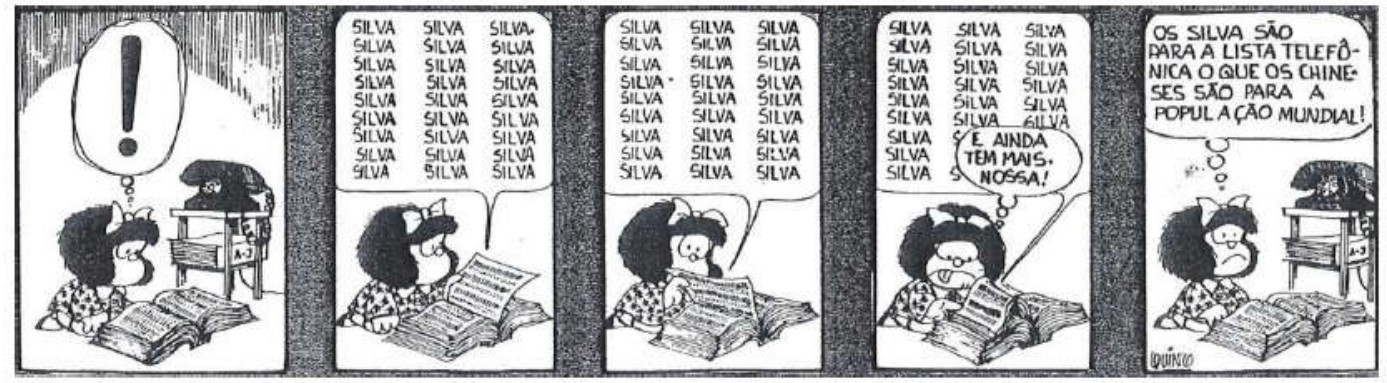

Figura 4: Extraído de PATOTA. Rio de Janeiro: Artenova, 1972-1974. Mensal. 27 volumes.

Segundo o Gran índice de heráldica e historia de apelidos (STATCOUNTER 2013), Pérez é um sobrenome patronímico que existe desde a Idade Média e é muito difundido na Espanha e na América Latina. Apesar de Pérez (e suas variações) ser um sobrenome conhecido no Brasil, os mais comuns e frequentes, de acordo com o Dicionário das Famílias Brasileiras (FRANÇA 1999), são Silva, Santos e Souza. Sendo assim, para conseguir um efeito de humor comparável sobre um leitor brasileiro, as três traduções optaram pela substituição do sobrenome Pérez por outro que fosse percebido no Brasil com uma abrangência semelhante, o sobrenome de origem portuguesa Silva, que classificamos como adaptação cultural. 
SILVA, B. Z. DA - Traduções dos nomes próprios nas histórias em quadrinhos: um estudo de caso das tiras de Mafalda, de Quino

\section{A tradução dos topônimos}

Segundo Nord (2003: 184), há também certas convenções relacionadas à tradução de nomes geográficos, os exônimos, que podem adquirir formas específicas em outras línguas. Eles podem diferir-se quanto à pronúncia (por exemplo, fr. Lille, pt. Lille), à ortografia (pt. Paris, es. París), à morfologia (pt. Vietnã, pt. eur. Vietname, in. Vietnam), à entidade lexical (rus. Москва, pt. eur. Moscovo, pt. Moscou; ch. Běijīng, pt. Pequim), alguns nomes voltam à forma latina antiga (de. Köln, pt. Colônia, es. Colonia) e outros são, inclusive, traduções literais (ned. Nederland, pt. Países Baixos). Na tradução de textos não-ficcionais convenciona-se usar geralmente o exônimo da cultura-meta de um nome de origem da cultura-fonte, se houver um.

No entanto, as tiras da Mafalda são textos ficcionais que tratam de topônimos não-ficcionais e seguem diferentes convenções. Há, por exemplo, a tirinha em que Mafalda vê um inseto se debatendo na janela por onde deseja sair, pois está preso. Para confortá-lo de que a situação dentro do cômodo é melhor do que a situação mundial, ela lê as seguintes manchetes do jornal para o inseto: "Dramática situación en Medio Oriente', 'Más víctimas en el Congo', 'Nuevo choque racial en EE.UU.', 'Disturbios en Pekín', 'Bombardeos en Vietnam'”. Essa tira, em especial, apresenta muitos topônimos e o tratamento dado a essas traduções foi diverso.
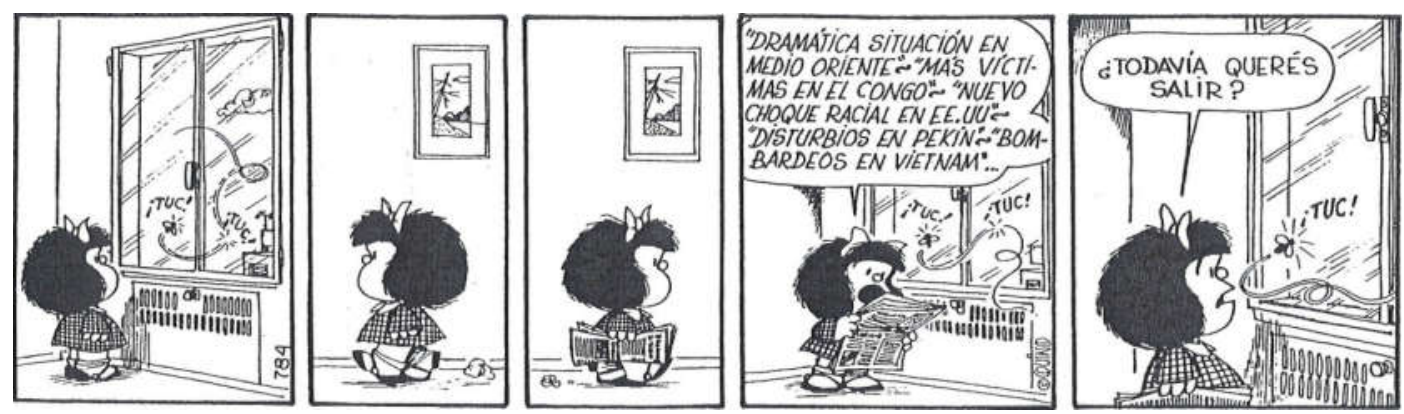

Figura 5: Extraído de QuINo. Toda Mafalda. 25. ed. Buenos Aires: Ediciones de la Flor, 2011. 
SILVA, B. Z. DA - Traduções dos nomes próprios nas histórias em quadrinhos: um estudo de caso das tiras de Mafalda, de Quino

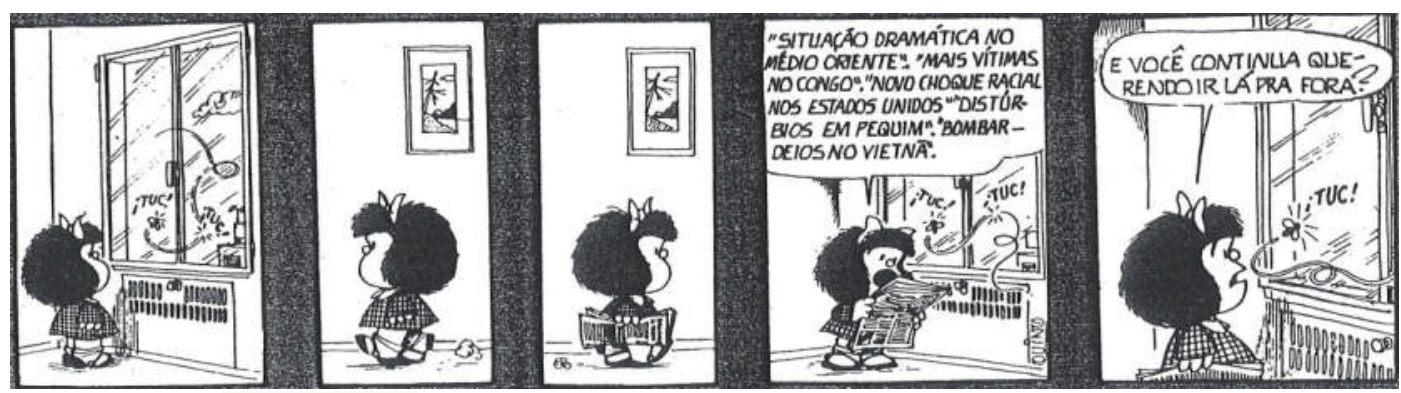

Figura 6: Extraído de PATOTA. Rio de Janeiro: Artenova, 1972-1974. Mensal. 27 volumes.
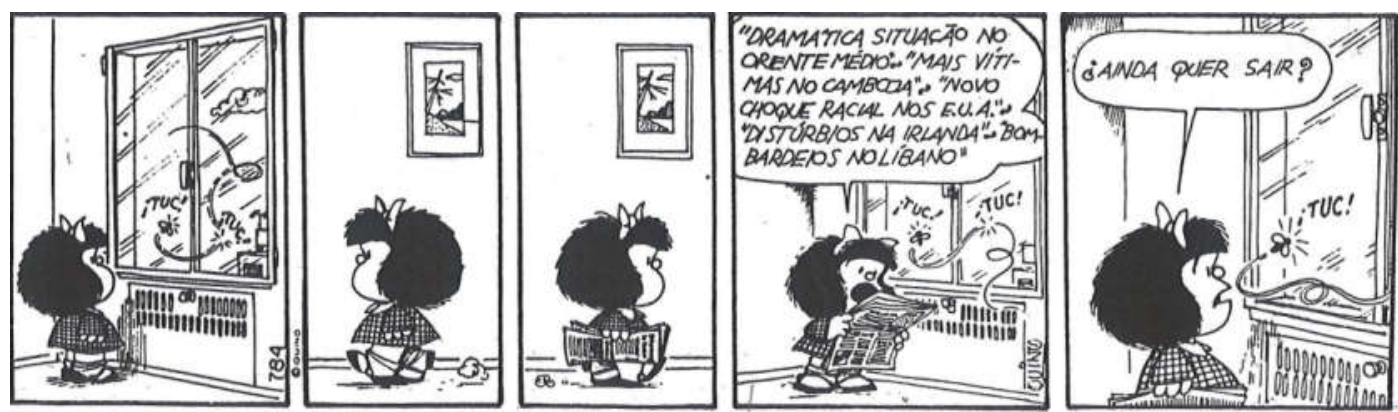

Figura 7: Extraído de QuINo. Mafalda 3. Tradução de Mouzar Benedito. São Paulo: Global, 1982.
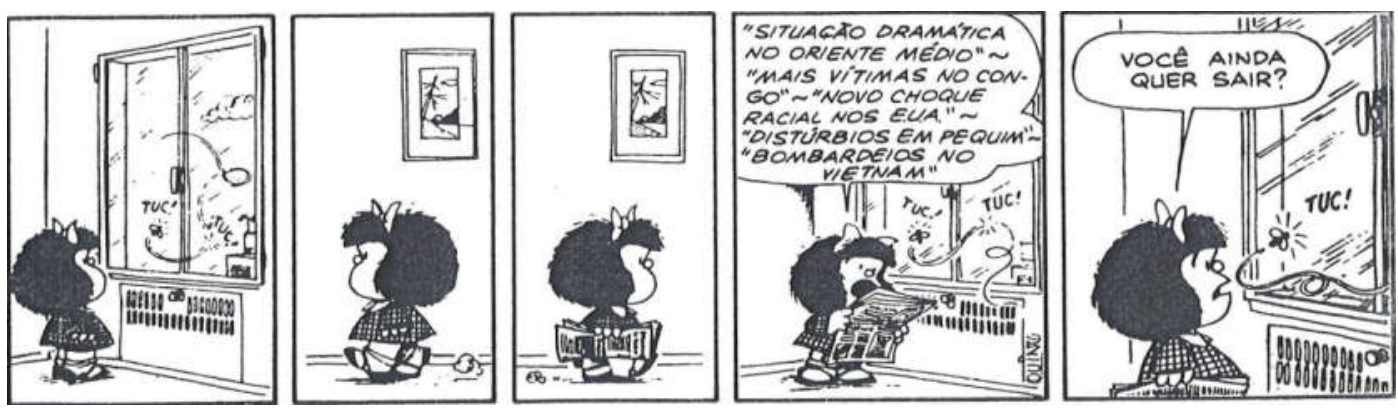

Figura 8: QUINO. Toda Mafalda. Trad. de Andrea Stael M. da Silva et al. São Paulo: Martins Fontes, 1991.

\subsection{Medio Oriente}

A opção da Editora Artenova foi não traduzir o topônimo, os tradutores o mantiveram conforme a LM “Médio Oriente", que divergiu somente quanto à ortografia e à pronúncia. Esse topônimo sofreu, portanto, uma interferência 
SILVA, B. Z. DA - Traduções dos nomes próprios nas histórias em quadrinhos: um estudo de caso das tiras de Mafalda, de Quino

lexical, ou seja, a operação realizada no nível da palavra foi influenciada pela proximidade gráfica entre as palavras do TF e do TM. Por outro lado, as editoras Global e Martins Fontes optaram pela tradução “Oriente Médio" e, dessa forma, realizaram uma transposição obrigatória, modalidade que ocorre quando a ordem das palavras tem que ser alterada, pois os tradutores não têm a opção de realizar uma tradução literal sem incorrer em erro gramatical.

\subsection{Congo}

O topônimo "Congo" é escrito da mesma forma na LF e na LM, sendo assim, as traduções da Artenova e da Martins Fontes realizaram a transcrição. Contudo, a Global optou por uma adaptação cultural e "Congo" se tornou "Camboja" nessa tradução em português.

\subsection{EE.UU.}

O topônimo "Estados Unidos" é abreviado em língua espanhola como “EE.UU.". Segundo o Diccionario panhispánico de dudas, da Real Academia Española, se na formação da abreviatura o truncamento deixa somente uma letra, o que seria considerado como o truncamento máximo, o plural se expressa com a duplicação dessa letra que deve ser seguida de um ponto. A opção tradutória da Artenova foi a explicitação da abreviatura para sua forma não abreviada "Estados Unidos” (pt.), dessa forma, as informações implícitas contidas no TF tornaram-se explícitas no TM. Em contrapartida, as traduções da Global e da Martins Fontes optaram pelo decalque da abreviatura e a mantiveram em sua forma usual em língua portuguesa "E.U.A." (pt.). 
SILVA, B. Z. DA - Traduções dos nomes próprios nas histórias em quadrinhos: um estudo de caso das tiras de Mafalda, de Quino

\subsection{Pekín}

A grafia do topônimo "Pekín” em língua espanhola difere-se da forma consagrada em língua portuguesa “Pequim”, opção tradutória das editoras Artenova e Martins Fontes, que classificamos como decalque. A editora Global, no entanto, optou mais uma vez pela adaptação cultural e traduziu “Pekín” por “Irlanda”.

\subsection{Vietnam}

As três editoras divergiram quanto às suas opções tradutórias de "Vietnam" (esp.). A Artenova adotou o topônimo consagrado em português "Vietnã", que classificamos como decalque; a Martins Fontes realizou uma interferência lexical ao manter o topônimo "Vietnam" e a Global optou por realizar uma adaptação cultural em que "Vietnam” (esp.) foi substituído por “Líbano".

Houve mais três casos de tradução de topônimos presentes em outras três tiras do corpus, são eles:

\subsection{Canal de la mancha}

O Canal da Mancha é uma faixa de água que liga o Oceano Atlântico ao Mar do Norte e, portanto, separa a França da Grã-Bretanha. Os ingleses o denominam de "English Channel" (O Canal Inglês) e os franceses de "La Manche" (A Manga). A tradução desse topônimo tanto em espanhol quanto em português deriva do francês, porém a partir de uma acepção equivocada de "manche" (fr.) como equivalente linguístico de "mancha, borrão, nódoa", quando o termo em francês refere-se, na verdade, à manga, a parte da roupa que circunda o braço. De todo modo, por tratar-se de uma tradução 
SILVA, B. Z. DA - Traduções dos nomes próprios nas histórias em quadrinhos: um estudo de caso das tiras de Mafalda, de Quino

consagrada em língua portuguesa, as três editoras optaram por traduzir "Canal de la Mancha" (esp.) por "Canal da Mancha" (pt.) e, segundo as modalidades de tradução, foram classificadas da seguinte forma: "Canal" como uma tradução literal, a contração “de la" (esp.) como uma transposição obrigatória em sua tradução para “da” (pt.), e o topônimo consagrado "Mancha" como uma transcrição.

\subsection{China}

Miguelito e Mafalda olham o mapa-múndi e ele diz "¡Claro, mirá China! ¡China tendría que estar amarilla!... ...jo roja!...” (esp.). Segundo o Diccionario panhispánico de dudas, da Real Academia Española, há certos topônimos em espanhol que incorporam os artigos definidos como parte fixa e indissociável do nome próprio como, por exemplo, no caso de "La Habana" (esp.) e "El Cairo" (esp.); e há outros nomes de países que podem ser empregados com ou sem os artigos definidos, como é o caso de "(la) China" (esp.). Quino optou por não empregar o artigo feminino "la” (esp.), possivelmente pelo desuso.

Em português, segundo a Nova Gramática do Português Contemporâneo (CUNHA; CINTRA 1985: 219-220), emprega-se normalmente o artigo definido com nomes de países, salvo exceções, e "a China" (pt.) é um desses casos. Devido a esse uso obrigatório do artigo feminino "a" (pt.) com o topônimo "China", opção das três traduções, classificamos "a China" como uma transposição obrigatória.

\subsection{Noruega}

Podemos observar no balão de pensamento de Mafalda a seguinte frase “Noruega. Nadie habla de Noruega” (esp.), cuja opção tradutória das três 
SILVA, B. Z. DA - Traduções dos nomes próprios nas histórias em quadrinhos: um estudo de caso das tiras de Mafalda, de Quino

editoras foi "Noruega. Ninguém fala da Noruega" (pt.). Em espanhol, esse topônimo não deve ser antecedido de artigo definido, e em português, por sua vez, o uso do artigo feminino singular "a" é obrigatório. Diferentemente da tradução de "China" apresentada acima, nesse caso, a diferença entre a presença ou não do artigo será marcada na preposição “de" (esp.) da regência do verbo "hablar" (esp.), sendo assim, o topônimo "Noruega", será classificado, portanto, como transcrição.

\section{Considerações Finais}

A partir da análise comparada entre as tiras de Mafalda e suas três traduções brasileiras, observamos que a técnica predominante nas traduções dos antropônimos foi a "não-tradução" e a modalidade que sobressaiu foi a transcrição, devido a presença de nomes familiares tanto da língua-fonte quanto da língua-meta e de nomes "não fictícios", que denominamos como biográficos, que são grafados da mesma forma na LF e na LM. A segunda modalidade mais frequente foi o empréstimo, em que foram classificados os nomes característicos da cultura-fonte que mantiveram nas traduções os sufixos de diminutivos "-ito" e "-ita" do espanhol.

No caso da tradução dos topônimos, a modalidade mais frequente foi a transcrição, nas traduções da Artenova e da Martins Fontes, que optaram pela “não-tradução”, e a adaptação cultural na tradução da Global, que optou por adaptar alguns nomes de países. As traduções da Global mantiveram-se mais próximas dos textos-fonte, porém realizaram adaptações temporais quando se tratou de traduzir alguns topônimos. Acreditamos que o tradutor tenha realizado tais adaptações, pois pretendia aproximar os leitores do TM aos países que eram retratados com frequência pelas notícias da época, contemplando a distância temporal entre o TF e a tradução. No entanto, o 
SILVA, B. Z. DA - Traduções dos nomes próprios nas histórias em quadrinhos: um estudo de caso das tiras de Mafalda, de Quino

tradutor não se deteve ao fato de que todos os países apresentados no TF tinham ligação ao comunismo e ao tema da Guerra Fria, muito recorrente nas tiras de Quino e contemporâneo às publicações da Mafalda.

Diante das observações apresentadas, percebemos que apesar de cada tradutor ter critérios particulares ao realizar suas próprias escolhas na tradução dos nomes próprios, eles seguiram certos padrões e convenções. 0 fator mercadológico foi determinante, afinal nenhum dos personagens principais teve seu nome traduzido e os exônimos, por sua vez, ora sofreram decalque, ora sofreram transposições obrigatórias para conformarem-se às convenções da língua-meta.

\section{Referências}

AUBERT, F. H. Modalidades de tradução: teoria e resultados. TradTerm. São Paulo, v. 5.1, pp. 99-128, 1998.

CIECHANOWER, M. Quino: Mafalda, enfant terrible de l'Argentine. In : Nuit blanche, le magazine du livre (Québec) n 38, pp. 52-56, 1989.

Cunha, C.; Cintra, L. Nova Gramática do Português Contemporâneo. Rio de Janeiro: Nova Fronteira, 1985: 219-220.

FrançA, R. Sabe com quem está falando? Revista Veja, São Paulo, edição 1 628, 2009. Disponível em: www.veja.abril.com.br/151299/p_108.html. Acesso em: 10 maio 2013.

González, M. L. C.; González, J. G. La traducción de los antropónimos. In: Revista española de lingüística aplicada. v. 7. 1991, pp. 49-72.

KaINDL, K. Comics in translation. In: Gambier, Y.; DoORSLAER, L. van (Edit.). Handbook of Translation Studies. Amsterdam/Philadelphia: John Benjamins, 2010. v.1, pp. 36-40.

NoRD, C. Proper names in translations for children: Alice in wonderland as a case in point. In: Meta. v. 48, n. 1-2, 2003: 182-196. Disponível em: www.id.erudit.org/iderudit/006966ar. Acesso em: 2 maio 2014.

PAтOTA. Rio de Janeiro: Artenova, 1972-1974. Mensal. 27 volumes. 
SILVA, B. Z. DA - Traduções dos nomes próprios nas histórias em quadrinhos: um estudo de caso das tiras de Mafalda, de Quino

QUINo. Mafalda inedita. Barcelona: Editoral Lumen, 1988.

- Mafalda 1. Tradução de Mouzar Benedito. São Paulo: Editora Global, 1982.

1982.

. Mafalda 2. Tradução de Mouzar Benedito. São Paulo: Editora Global, . Mafalda 3. Tradução de Mouzar Benedito. São Paulo: Editora Global, 1982. 1982.

. Mafalda 4. Tradução de Mouzar Benedito. São Paulo: Editora Global, . Mafalda 5. Tradução de Mouzar Benedito. São Paulo: Editora Global, 1982.

. Toda Mafalda. 25. ed. Buenos Aires: Ediciones de la Flor, 2011.

. Toda Mafalda. Tradução de Andrea Stael M. da Silva et al. São Paulo: Martins Fontes, 1991.

ReAl aCADEMIA esPanhola. Diccionario panhispánico de dudas. Disponível em: www.rae.es/diccionario-panhispanico-de-dudas/apendices/paises-y-capitalescon-sus-gentilicios. Acesso em: 28 abr. 2014.

REIS, D. S. Tradução e formação do Mercado Editorial dos Quadrinhos no Brasil. III Jornada de Estudos sobre Romances Gráficos, 2013, Brasília. Anais da III Jornada de Estudos sobre Romances Gráficos 2012, 2013: 126-136.

SILVA, B. Z. As tiras de Mafalda no Brasil: tradutores e traduções. 2015. $229 f$. Dissertação (Mestrado em Língua Espanhola e Literaturas Espanhola e HispanoAmericana) - Faculdade de Filosofia, Letras e Ciências Humanas, Universidade de São Paulo, São Paulo, 2015.

StATCOUNTER. Gran índice de heráldica e historia de apelidos. Disponível em: www. heraldicapellido.com. Acesso em: 10 maio 2013. 